\section{Silver anniversary for BSG}

This year the British Society of Gerodontology (BSG) is 'Celebrating silver': their 25th anniversary.

In June, the Honorary President, Dr Heather Lloyd, Specialist in Special Care Dentistry and Honorary Senior Lecturer at the University of Kent, welcomed delegates to the Spring Conference in Shrewsbury.

The theme of 'Celebrating silver' included a wide scope of issues relevant to gerodontology for an audience of dentists working in special care dentistry, general dental practitioners and dental care professionals (DCPs). Dr Cathryn Mainwaring discussed pertinent issues in geriatric medicine such as DNACPRs and palliative care through case discussion of aspiration pneumonia; Professor StJohn Crean presented the research links between oral health and dementia; and Julie Procter, a dentist who cared for her mother with dementia, gave an inspiring and emotional account of her story. There was a practical and pragmatic presentation led by Dr Malcolm Edwards discussing options for older patients with a compromised dentition, strategies intervention.

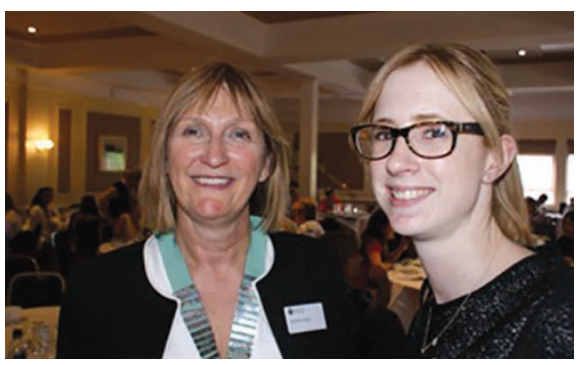

Dr Heather Lloyd (left) with Dr Cathryn Mainwaring at the BSG's Spring Conference

for managing tooth wear and methodical approaches with techniques for minimal

One of BSG's aspirations is to further its work with and in support of DCPs and it is proud to have Rosalyn Davies, Dental Programme Manager, 1,000 Lives Service Improvement for Public Health Wales, as President-elect for 2017. Rosalyn will be the society's first DCP president.

BSG's Winter Conference will be held on 1 December in London with the theme of 'Safeguarding for the future'. For further information and details of the society's work, visit www.gerodontology.com.

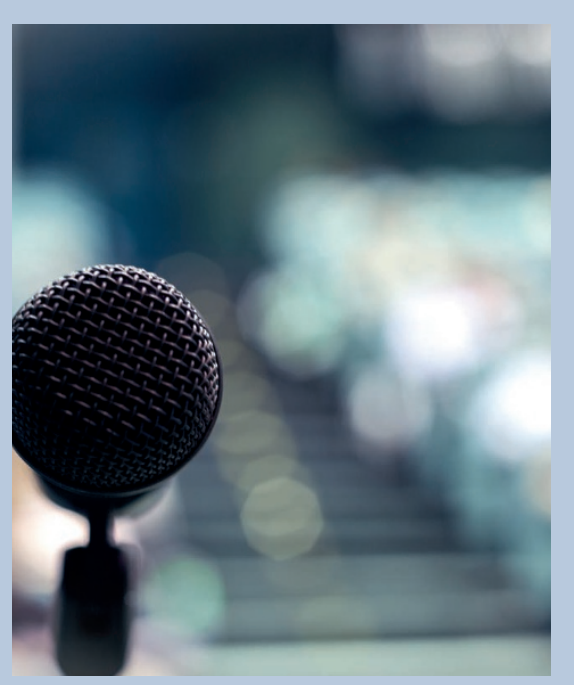

are available on a first come first served basis. Demand is expected to be high and places are limited. To request a ticket email winterlecture@bda.org confirming your name and BDA membership number. Further details about the event are available at www.bda.org/ winterlecture

A recording of the lecture will be made available shortly after the event for all members to view online.
BDA branch meetings

\section{East Midland Branch}

East Midland Branch will hold their Annual General Meeting on Wednesday 5 October from $7.30 \mathrm{pm}$ at the Novotel Nottingham Derby (Long Eaton), Bostock Lane, Long Eaton, NG10 4EP. The meeting will be followed by an educational presentation by Professor Tara Renton, King's College London Dental Institute, on orofacial pain. To offer apologies for this meeting please contact the Branch Secretary, Julie Kirkby on eastmidsbda@gmail.com. Booking is not necessary to attend the educational meeting.

\section{Metropolitan Branch}

Metropolitan Branch will hold their Annual General Meeting on Wednesday 5 October at the BDA, 64 Wimpole Street, London, W1G $8 Y S$ at $6.45 \mathrm{pm}$, and will be followed by an educational presentation by Dr Linda Greenwall and Professor Jean Pierre Attal (Paris) on minimal invasive aesthetic treatments and resin infiltration. Branch are also looking for nominations for President Elect and President Designate, all nominations with CV welcome, to Branch Secretary, Nazli Imtiaz at nazliimtiaz@gmail.com; apologies for the AGM can also be sent to Nazli at this same address.

\section{South Wales Branch}

The South Wales Branch Annual General Meeting will be held on Friday 4 November at the Vale Resort, Hensol Park, Vale of Glamorgan. The Branch will also be holding their Winter Study meeting on the same day with speakers Nick Drage: Dental radiology - the latest guidance (CORE CPD), Sue Greening: Special Care Dentistry - working together across Wales, Meryl Spencer: Orthodontics - what to refer and when, David Lauder: Consent - an update (Recommended $C P D)$, Professor Mike Lewis and Anwen Cope: Antibiotic prescribing: the impact of getting it wrong!, and Andrew Keeling: Occlusion - modern practice and future innovation. You can find more information about the meeting on the BDA events pages of the website. If not attending the meeting, apologies for the AGM can be sent to John Perry, Branch Secretary at bdasouthwales@ gmail.com. 